\title{
3. DECISÃO CAUTELAR DO SUPREMO TRIBUNAL FEDERAL QUE CONSIDEROU CONSTITUCIONAL LEICARIOCA QUE PREVE DESCONTOS NO PREÇO DE REMÉDIOS PARA IDOSOS
}

\section{Ementário n. 2 130-2 Tribunal Pleno}

Ação Direta de Inconstitucionalidade n. 2.435-3 - RJ (Medida Liminar)

Requerente: Confederação Nacional do Comércio

Requerido: Governador do Estado do Rio de Janeiro

Requerida: Assembléia Legislativa do Estado do Rio de Janeiro

Relatora: Ministra Ellen Gracie

Ementa: Ação direta de inconstitucionalidade. Lei n. 3.542/01, do Estado do Rio de Janeiro, que obrigou farmácias e drogarias a conceder descontos a idosos na compra de medicamentos. Ausência do periculum in mora, tendo em vista que a irreparabilidade dos danos decorrentes da suspensão ou não dos efeitos da lei se dá, de forma irremediável, em prejuízo dos idosos, da sua saúde e da sua própria vida. Periculum in mora inverso. Relevância, ademais, do disposto no art. 230, caput da CF, que atribui à família, à sociedade e ao Estado o dever de amparar as pessoas idosas, defendendo sua dignidade e bem-estar e garantindo-lhes o direito à vida. Precedentes: ADI n. 2.163/RJ e ADI n. 107-8/AM. Ausência de plausibilidade jurídica na alegação de ofensa ao $\S 70$ do art. 150 da Constituição Federal, tendo em vista que esse dispositivo estabelece mecanismo de restituição do tributo eventual ente pago a maior, em decorrência da concessão do desconto ao consumidor final. Precedente: DI n. 1.85 1/AL. Matéria relativa à intervenção de Estado no domínio econômico relegada ao exame do mérito da ação.

Medida liminar indeferida.

\section{ACÓRDÃO}

Vistos, relatados e discutidos estes autos, acordam os Ministros do Supremo Tribunal Federal, em Sessão Plenária, na conformidade da ata de julgamento e das notas taquigráficas, por maioria de votos, indeferir a medida liminar. 


\section{RELATÓRIO}

\section{A Senhora Ministra Ellen Gracie:}

1 - Trata-se de ação direta de inconstitucionalidade ajuizada pela Confederação Nacional do Comércio, impugnando a Lei n. 3.542, de 16 de março de 2001, do Estado do Rio de Janeiro, cujo teor é o seguinte: "Art. 1ำ Ficam as farmácias e drogarias localizadas no Estado do Rio de Janeiro obrigadas a conceder desconto na aquisição de medicamentos para consumidores com mais de 60 (sessenta) anos, na seguinte proporção: a) consumidores de 60 a 65 anos - 15\% de desconto; b) consumidores de 65 a 70 anos - $20 \%$ de desconto; c) consumidores maiores de 70 anos $-30 \%$ de desconto. Art. $2^{\circ} \mathrm{O}$ desconto será concedido mediante a apresentação de Carteira de Identidade e da receita médica por parte do consumidor. Art. $3^{\circ} \mathrm{O}$ não cumprimento das disposições desta Lei ensejará a aplicação de multa em valor equivalente a 5.000 UFIR's por infração, a ser aplicada pela Secretaria de Estado de Saúde. Art. 4 Esta lei entra em vigor na data de sua publicação, revogadas as disposiçōes em contrário." Alega a requerente que essa lei ofende os seguintes dispositivos constitucionais: arts. 1․, IV; 30, IV; 50, caput e incisos XIII e XXII; 150, IV; 170, caput e incisos II e IV, e 174, todos da CF. Entende que essa norma, ao obrigar as farmácias e drogarias a conceder desconto no preço dos remédios, viola os princípios da livre concorrência e da livre iniciativa (art. 170, capute inciso IV da CF), consistindo em indevida intervenção do Estado na ordem econômica. Aduz que a intervenção do Estado só se pode dar de 02 (duas) formas: direta e indireta. Diretamente, quando o Estado explora, ele mesmo, determinada atividade econômica, nas hipóteses expressas na Constituição, ou seja, quando tal intervenção é necessária aos imperativos da segurança nacional ou a relevante interesse coletivo' (art. 173, caput). Indiretamente, atuando corno agente normativo e regulador, exercendo, na forma da lei, as funçōes de fiscalização, incentivo e planejamento, sendo este determinante para o setor público e indicativo para o setor privado (art. 174, caput). Expressa que a "concessão de descontos para idosos em medicamentos pelo Governo carioca não implica em qualquer forma de fiscalização ou incentivo no setor farmacêutico e sim INTROMISSÃO INDEVIDA DO PODER PÚBLICO NO DIREITO QUE A LIVRE INICIATIVA POSSUI, NUMA ECONOMIA DE MERCADO DE PLANEJAR SEUS PREÇOS, NUMA PERSPECTIVA DE LIVRE CONCORRÊNCIA ENTRE OS EMPRESÁRIOS DAQUELA CATEGORIA ECONÔMICA". Cita em abono de sua tese o decidido por esta Casa no RE n. 199.517 (rel. p/acórdão - Min. Maurício Corrêa), em que foi declarada inconstitucional, por ofensa aos princípios da livre iniciativa e da livre concorrência, lei do Município de Campinas que impunha limitação geográfica para a instalação de drogarias, consistente em distância mínima entre uma e outra. Entende também haver ofensa ao art. $3^{\circ}$, IV da CF, pois a lei, ao eleger o elemento idade como critério de concessão dos descontos, contrariou esse preceito, segundo 
o qual um dos objetivos da República Federativa do Brasil é o de promover o bem de todos, sem preconceito de idade, entre outros. Alega que o critério da idade, simplesmente, não expressa o estado de necessidade e a capacidade contributiva do beneficiário, que poderia ser, no caso, tanto um idoso rico quanto um pobre, desvirtuando-se a finalidade do texto legal. Por fim, visualiza contrariedade ao princípio da isonomia (art. 5․, caput da CF), tendo em vista conceder a lei aos idosos tratamento privilegiado em detrimento dos demais consumidores de medicamentos que se encontram na mesma situação financeira, sejam crianças, idosos, deficientes ou desempregados. Vê ofensa a esse princípio, também, no tratamento diferenciado dado às farmácias e drogarias localizadas no Estado do Rio de Janeiro em relação às demais localizadas em outros lugares do território nacional, possibilitando que o empresário sediado fora desse Estado possa fixar livremente seus preços de acordo com as leis de mercado, ao passo que aquele radicado no Rio de Janeiro deve, compulsoriamente, praticar preços com os aludidos descontos, o que violaria também o princípio da livre concorrência. Pede concessão de liminar para que sejam sustados os efeitos da lei impugnada.

2 - A Assembléia Legislativa do Estado do Rio de Janeiro, nas suas informações (fis. 81/100), aduz que a lei impugnada faz parte da política adotada por tal Estado em defesa das pessoas da terceira idade, sendo decorrência do disposto nos arts. $1^{\circ} \mathrm{III} ; 3^{\circ}, 1$ e 230, todos da CF. Entende que a intervenção do Estado, no caso, limitando o lucro, é legítima, justificandose em razão da sua finalidade social e por ser em favor de uma parcela da população que necessita de especial proteção. Quanto a eventual ofensa ao princípio da isonomia, pelo fato de a limitação imposta aos estabelecimentos sediados no Estado do Rio de Janeiro não se estender àqueles localizados em outros Estados, aduz ser impertinente, eis que a concorrência entre farmácias, tendo em vista a natureza dos produtos comercializados, se dá apenas em âmbito municipal. Defende também estar presente o princípio da isonomia na eleição do idoso como beneficiário da lei, principalmente tendo em conta a especial situação dessa camada da população no país: não bastasse uma redução da capacidade de esforço físico, refletindo uma diminuição da sua força laborativa, o idoso tem, ainda, os seus rendimentos reduzidos pelo limite imposto pelo Regime Geral da Previdência Social. A aplicação da isonomia, consistindo no tratamento desigual de situações desiguais, na medida em que se desigualam, estaria perfeitamente atendida no caso. Assevera ainda que a norma em destaque está em consonância com o princípio da razoabilidade, pois estabelece requisitos que devem ser observados para a fruição do benefício legal e, também, se destina a um público que, no Estado do Rio de Janeiro, corresponde a 9 (nove por cento) da população local, segundos dados do IBGE.

3 - O Governador do Estado do Rio de Janeiro também apresentou informações (141/147), sustentando, de início, que a lei atacada tem como objetivo dar eficácia às normas programáticas insertas nos arts. 1ํ, III (que 
fixa a dignidade da pessoa humana como um dos fundamentos da nossa República); 3ㅇ, I (que elege como um dos objetivos da República o de construir uma sociedade livre, justa e solidária) e 230 , caput (que confere à família, à sociedade e ao Estado o dever de amparar as pessoas idosas, garantindoIhe dignidade, bem-estar e o direito à vida). A defesa desses princípios, no seu entendimento, legitima a intervenção do Estado no domínio econômico, estando justificada a limitação do lucro pela finalidade social do respectivo controle, exercido no caso em favor de uma parcela da população que, inegavelmente, necessita de proteção especial. Pelas mesmas razões explanadas nas informações da Assembléia Legislativa, não vê violência, ao princípio da isonomia. Espera o indeferimento da liminar.

4 - Havendo pedido de liminar, submeto-o à apreciação do Plenário.

É o relatório.

\section{VOTO}

A Senhora Ministra Elien Gracie (Relatora): O Plenário desta Corte, na sessão de 29.06.00, por unanimidade, indeferiu liminar postulada pela Confederação Nacional do Comércio em ação direta contra a Lei n. 3.364/ 00, do Estado do Rio de Janeiro (ADI n 2.163, rel. Min. Nelson Jobim), que dispõe sobre o pagamento de meia-entrada em casas de diversões, praças desportivas e similares, beneficiando os jovens de até 21 anos de idade. Naquela assentada, entendeu o Plenário que, no caso, o risco de grave dano seria de maior prejuízo aos menores de 21 anos, que, caso deferida a liminar mas vindo a ser julgada improcedente a ação, ficariam a descoberto do pagamento da meia-entrada, o que dificultaria seu acesso aos eventos, com prejuízo irreparável. Quanto aos empresários, caso indeferida a liminar mas no mérito julgada procedente a ação, saberiam eles como se ressarcir dos prejuízos que porventura julgassem haver sofrido. Pelo mesmo fundamento também indeferiu-se liminar na ADI n. 107-8/AM, rel. Min. Célio Borja, que envolveu questão referente a isenção de tarifa nos transportes coletivos a deficientes, idosos, policiais e estudantes, implementada por norma constitucional estadual. O presente caso é semelhante. A lei estadual impugnada obriga as farmácias e drogarias a conceder descontos, na compra de medicamentos, a uma parcela da população que, por força do disposto no art. 230 da Constituição Federal, merece tratamento especial por parte da família, do Estado e da sociedade - as pessoas idosas. Caso deferida a liminar mas vindo a final a ser julgada improcedente a ação, as pessoas idosas ficariam, nesse interregno, despidas da facilidade legal que lhes garante, sem dúvida, acesso a medicamentos vitais para o seu bem-estar e sua dignidade, garantindo, assim, seu direito à vida (art. 230, caput da Carta Política). Quanto aos empresários, caso indeferida a liminar mas no mérito julgada procedente a ação, terão condições de se ressarcir, pelas regras de mercado, dos prejuízos 
que porventura julgarem haver sofrido, levando-se em conta, também, a informação prestada pela Assembléia Legislativa (f. 81/100) de que o públicoalvo da lei questionada corresponde a apenas $9 \%$ da população do Estado do Rio de Janeiro. A irreparabilidade dos danos decorrentes da suspensão ou não dos efeitos da lei, parece evidente, se dá, de forma irremediável, em prejuízo dos idosos, da sua saúde e da sua própria vida, valores mais caros à República Federativa do Brasil (art. 1으. III e IV e art. 3ํ, I e IV da CF) do que eventual prejuízo parcial de determinado ramo comercial, insuscetível de inviabilizar a continuidade empresarial e passível de reparação posterior por mecanismos de mercado. A hipótese é, portanto, de periculum in mora inverso. Sendo este um dos requisitos necessários para a concessão da medida liminar, sua ausência no caso leva-me a indeferir a cautela pretendida, a exemplo do que fez este Plenário nos precedentes apontados. Quanto ao fundamento realçado da tribuna pelo ilustre advogado da requerente, de que os medicamentos se submetem ao regime de substituição tributária, reputo-o despido de plausibilidade jurídica. Segundo argumentou, a obrigatoriedade de concessão de descontos desvirtuaria tal sistema de substituição, tendo em vista que o ICMS é recolhido pelo substituto com base em valor presumido, o qual não corresponderia àquele decorrente do desconto na venda ao consumidor final. No entanto, observo que o art. $150, \S 7^{\circ} \mathrm{da}$ Constituição Federal, visando justamente a equacionar situações como essa, criou um mecanismo de restituição do valor do tributo eventualmente pago a maior. O Plenário desta Corte, ao julgar a medida cautelar na ADIn n. 1.85 1/AL, rel., o Min. Ilmar Galvão, suspendeu os efeitos da Cláusula Segunda do Convênio ICMS 13/07, que vedava a restituição ou a cobrança complementar do ICMS quando a operação ou prestação subseqüente à cobrança do imposto, sob a modalidade de substituição tributária, se realizasse com valor inferior ou superior àquele estabelecido com base no art. $8^{\circ}$ da Lei Complementar n. 87, de 13 de setembro de 1996. A suspensão se deu justamente por haver afronta, nessa proibição, ao disposto no $\S 7^{\circ}$ do art. 150 da Carta Política. Entendo ser de bom alvitre, ainda, pela sua importância e complexidade, relegar ao exame de mérito a apreciação da questão referente à possibilidade de intervenção no domínio econômico por parte de Estadomembro, diante da competência concorrente para legislar sobre direito econômico estatuída no art. 24, I da Constituição Federal. Anoto que, no tocante à intervenção da União, o Plenário desta Casa, no julgamento da ADIn n. 319/DF, rel. o Min. Moreira Alves, que envolvia questão relativa à fixação de índice para reajuste de mensalidades escolares (Lei n. 8.039/ 90), reconheceu a legitimidade constitucional da intervenção do Estado no domínio econômico para salvaguardar valores relacionados com a garantia de existência digna a todos, conforme os ditames da justiça social, valores que orientam a ordem econômica, nos termos do art. 170 da Carta Magna. Diante do exposto, indefiro a medida liminar, por ausência de periculum in mora. 


\section{VOTO}

O Senhor Ministro Nelson Jobim: Sr. Presidente, não adentro na parte relativa à questão da substituição tributária, que entendo de outra forma, tendo em vista o texto da Constituição; não acompanho a Ministra Ellen Gracie naquele fundamento. Quanto ao problema do risco da mora, considerando que existe uma norma vigendo há quase um ano, acompanho-a pelas razōes específicas.

\section{VOTO}

O Senhor Ministro Marco Aurélio (Presidente): Vou pedir vênia à ministra Ellen Gracie para adotar uma posição antipática àqueles que contam com mais de sessenta anos de idade. Não o faço por estar distante dessa faixa etária, mas por estar convencido da falta de proporcionalidade e - perdoem-me, já que se trata de um instituto jurídico - de razoabilidade da norma. Na Lei n. 3.542, de 16 de março de 2001, do Estado do Rio Janeiro, preceitua-se: "Art. $1^{\circ}$ Ficam as farmácias e drogarias localizadas no Estado do Rio de Janeiro obrigadas a conceder desconto na aquisição de medicamentos para consumidores com mais de 60 (sessenta) anos, na seguinte proporção: a) consumidores de 60 a 65 anos - 15\% de desconto; b) consumidores de 65 a 70 anos - $20 \%$ de desconto; c) consumidores maiores de 70 anos $-30 \%$ de desconto. Art. $2^{\circ} \mathrm{O}$ desconto será concedido mediante a apresentação da Carteira de Identidade e da receita médica por parte do consumidor. Art. $3^{\circ} \mathrm{O}$ não-cumprimento das disposições desta Lei ensejará a aplicação de multa em valor equivalente a 5.000 UFIR's por infração, a ser aplicada pela Secretaria de Estado de Saúde. Art. 42. Esta Lei entra em vigor na data de sua publicação, revogadas as disposições em contrário." Pois bem, de acordo com a Carta da República, incumbe ao Estado-gênero proporcionar, aos menos afortunados, a saúde e os meios indispensáveis para alcançá-la. Ora, sabendo que nesse campo, é de indagar se ao Estado é possível, mediante atuação de dois de seus Poderes, transferir esse ônus ao particular. Há um outro aspecto - por isso aludi à proporcionalidade: é que, na hipótese concreta, não se distingue quanto à possibilidade de aquisição dos remédios, considerado o preço, por aqueles que, estando aquém das faixas etárias referidas, não têm condição de comprar, só o fazendo com o sacrifício da própria alimentação. Na lei não se cogita, sequer - aí, eu diria que o legislador acabou cumprimentando com chapéu alheio - , de uma compensação, tendo em vista a postura do próprio Estado, na condição de credor do Imposto sobre Circulação de Mercadorias e Serviços. Simplesmente, na lei impõem-se os descontos, sem se atentar para a situação financeira do adquirente do remédio, bastando o fator objetivo "idade", e, ainda, prevê-se, em caso de desobediência, multa pesada no importe de 5.000 UFIR's. Essa intervenção do Estado, a meu ver, diverge das normas básicas da Constituição Federal. Trata-se, sob a minha óptica e com a devida vênia 
dos colegas - torno a ressaltar o alcance social do diploma -, de uma interferência no domínio econômico, que discrepa, principalmente, do art. 174 da Carta da República. De qualquer forma, de duas, uma: ou a farmácia arcará com o ônus do desconto, ou majorará os preços dos remédios, ficando apenada toda a população. Por isso, peço vênia - principalmente numa época em que se busca preservar a estabilidade da moeda, afastando-se do cenário jurídico o aumento de preço - para deferir a liminar.

\section{COMENTÁRIOS}

Geisa de Assis Rodrigues (*)

Nos presentes comentários daremos ênfase à discussão constitucional sobre a prevalência do direito dos idosos sobre os interesses dos agentes econômicos, não nos aprofundando seja na temática tributária, seja na de Direito da concorrência, que são também suscitadas na decisão.

O presente julgado do Supremo Tribunal Federal é bastante interessante porque enfrentou o conflito entre a proteção de direitos fundamentais - como o direito à vida, à saúde e à defesa do consumidor pelo Estado - da parcela da sociedade carioca que conta com mais de sessenta anos, e a liberdade de atuação do domínio econômico das farmácias e drogarias do Estado do Rio de Janeiro, também garantida em sede constitucional.

Ora, esse debate é típico do constitucionalismo contemporâneo, caracterizado também pelo fenômeno da constitucionalização das relações privadas $^{(1)}$, transformando o estatuto jurídico do político, na consagrada expressão de Canotilho(2), no estatuto jurídico da vida, pois a Constituição é o diploma que estabelece as regras mais importantes da convivência humana, e não só as relativas à organização do Estado. Não por acaso a Constituição de 1988 considera a defesa do consumidor a ser promovida pelo Estado como um direito fundamental, expressamente previsto no rol de sua declaração de direitos (art. $5^{\circ}$, XXXII). Também a defesa do consumidor assume uma importância principiológica no desenvolvimento da atividade econômica, como um valor que deva necessariamente ser atendido pela ordem econômica do Estado Democrático de Direito (art. 170, V da CF). A mais importante mensagem da norma constitucional é a necessidade do novo código respeitar a importância das pessoas na economia de mercado.

(*) Professora licenciada da graduação e da pós-graduação da Faculdade de Direito da Universidade Federal da Bahia. Procuradora Regional da República na $3^{a}$ Região. Mestre e Doutora pela Universidade do Estado do Rio de Janeiro.E-mail:<geisarodrigues@uol.com.br.>.

(1) FLÓREZ-VALDÉS, Joaquín Arce. El derecho civil constitucional. Madrid: Cuadernos Civitas, 1991.

(2) CANOTILHO, J. J. Gomes. Direito constitucional e teoria da Constituição. Coimbra: Almedina, 1998. 
Ao mesmo passo, o neoconstitucionalismo enfatiza a relevância dos direitos sociais, como o direito à saúde arrolado no art. 6 da Constituição. Nas palavras do texto constitucional a saúde é um direito de todos e um dever do Estado, devendo ser implementada mediante a adoção de políticas econômicas e sociais que visem à redução do risco de doenças e de outros agravos e ao acesso universal e igualitário às ações e serviços para sua promoção, proteção e recuperação.

E mais, o efetivo exercício do direito à saúde é condição básica para garantia do mais importante dos direitos, que é o direito à vida. A preservação da saúde mantém a possibilidade da própria continuidade da vida; a higidez física e mental qualifica a vida harmônica.

Ademais, temos expressa previsão no art. 230 de nossa Carta Magna acerca da especial proteção das pessoas idosas, tendo o Estado, a família e a sociedade o dever de ampará-las e de defender a sua dignidade, o seu bem-estar e o seu direito à vida. A Constituição, como o faz em inúmeras passagens, elegeu um critério de discrímen para favorecer a proteção dos idosos em virtude de sua notória fragilidade em relação aos demais integrantes adultos da sociedade.

Há, de conseguinte, um direito fundamental à vida e à saúde, bem como um direito fundamental à especial defesa do consumidor pelo Estado, que se revelam ainda mais intensos quando seu titular é pessoa idosa.

Com efeito, a idéia de existência de direitos tão fundamentais que deveriam ser atribuídos a todos os indivíduos nasce com o próprio surgimento do constitucionalismo. Ainda que tenhamos antecedentes mais remotos de declarações de direitos desde a Idade Média, como a célebre Magna Carta, é no movimento constitucionalista do século XVIII que encontramos por primeiro a importância do reconhecimento formal de direitos que pertencem ao Homem pelo simples fato de sê-lo. Além da conformação do poder político, a Constituição é, desde sempre, a lei que veicula esses direitos essenciais.

Em sendo a definição de direitos fundamentais um conceito histórico e político é natural a existência de uma viva controvérsia sobre o seu conteúdo. As concepções mais restritas limitam os direitos fundamentais aos direitos civis individuais clássicos, aqueles que se consagraram para inibir o abuso estatal, protegendo a esfera da liberdade do indivíduo. A despeito da ordem constitucional de vários países incluir no rol de sua declaração direitos de índole social e econômica, considera-se que apenas alguns deles são ontologicamente fundamentais, sob o argumento de que se deve preservar 0 que realmente é relevante para a pessoa humana.

Outros também açambarcam na categoria de direitos fundamentais as novas geraçōes ${ }^{(3)}$ de direitos, como os sociais, os difusos e alguns individuais

(3) BOBBIO, Norberto. A era dos direitos. Tradução de Carlos Nelson Coutinho. Rio de Janeiro: Ed. Campus, 1992. 
que assumem uma nova conotação jurídica, como os direitos da personalidade, quando expressamente arrolados no texto constitucional. As características desses direitos como a exigência de prestações positivas do Estado para atendê-los, a titularidade coletiva e a abrangência de novos bens jurídicos, não servem para desnaturar a essência fundamental proclamada pelo constituinte.

A controvérsia não tem exclusivo interesse acadêmico, pois existem importantes implicaçōes na qualificação de um direito como fundamental, sobretudo relacionadas à sua eficácia, ao compromisso jurídico de sua concretização. É importante ressaltar que a categoria de direito fundamental não obedece a uma lógica cartesiana, ou seja, não resulta da apreensão da realidade fática como a razão humana a percebe. É um conceito cultural, como de resto todos os conceitos jurídicos. Portanto, nada mais razoável que o rol dos direitos fundamentais tenha uma dimensão histórica e espacial, sendo uma definição em constante evolução. Negar a um novo legislador constituinte a definição do que se considera como direito fundamental é impor às atuais e futuras geraçōes o ideário dos que já se foram. Contudo, nunca é demais lembrar que uma simples qualificação jurídica não tem o condão de alterar a realidade, nem as vicissitudes da realização de cada tipologia de direito em um dado contexto econômico e social(4).

Assim, será direito fundamental o que a Constituição considerar como tal, e a mesma o faz tanto em relação ao direito à vida, à saúde, à defesa do consumidor pelo Estado e à proteção especial do idoso pela família, pelo Estado e pela sociedade. A decisão comentada, embora não seja explícita quanto à essência fundamental desses direitos os valora nesse sentido, ao não afastar a lei carioca que prevê a concessão de descontos em medicamentos, ainda que em juízo preliminar, do nosso ordenamento jurídico.

O consumo de medicamentos deve ser examinado sob a perspectiva de constituir uma via de se garantir esses direitos fundamentais, pois a necessidade deste consumo revela, hoje, a premência de uma cidadania econômica, no dizer do saudoso professor Milton Santos( ${ }^{(5)}$. Nem se diga que a importância do consumidor é menos intensa em países de economia periférica como a nossa, porque, como defende Herman Benjamim, "é necessário que enxerguemos a proteção do consumidor como uma manifestação universal, inerente à modernidade, à economia de mercado e à sociedade de consumo"(6).

(4) Canotilho observa, com a argúcia que lhe é peculiar, que "a reserva dos cofres do Estado" coloca problemas de financiamento mas não implica o grau zero de vinculatividade jurídica dos preceitos consagradores de direitos fundamentais sociais". CANOTILHO, J. J. Estudos sobre direitos fundamentais. Metodologia "fuzzy" e "camaleöes normativos" na problemática atual dos direitos econômicos, sociais e culturais. Coimbra: Coimbra Editora, 2004.p. 109

(5) SANTOS, Milton. O país distorcido: o Brasil, a globalização e a cidadania. São Paulo: Publifolha, 2002.

(6) BENJAMIN, Herman. A proteção do consumidor nos países menos desenvolvidos: a experiência da América Latina, in Revista do Direito do Consumidor, São Paulo, n. 8, p. 201. 
Nunca se deve olvidar, outrossim, que o consumidor, aquele que adquire um produto como destinatário final, sem que o mesmo lhe gere algum tipo de riqueza, é o elo final na cadeia econômica, e guarda assim um distanciamento quanto ao processo de produção dos bens ou da prestação dos serviços que thes são destinados. Por tudo isso, tem o consumidor uma posição ontologicamente mais débil em todo o processo produtivo, estando, em maior ou menor grau, sempre "sujeito à sujeição"(7).

Assim, as normas constitucionais que incidem na proteção do idoso consumidor de medicamentos revelam uma ampliação do objeto tradicional da Constituição, uma percepção de que os hipossuficientes não podem mais ser relegados à própria sorte na esfera de suas relações com os demais agentes econômicos. Assim, a defesa do consumidor idoso é uma obrigação do Estado que tem reflexos nas relações econômicas privadas. Por isso, a execução desse direito tem uma dimensão vertical, posto que pressupōe cumprimento de deveres jurídicos pelo Estado para com o consumidor. Mas também tem importantes impactos na dimensão horizontal da proteção de direitos fundamentais ${ }^{(8)}$, porque implica a necessidade de observância de determinados padrões por todos, e, na hipótese examinada, pelo segmento de farmácias do Estado do Rio de Janeiro. Tal conclusão é reforçada, pois a Constituição considera a defesa do consumidor como um princípio da ordem econômica, a enfatizar essa ampla vinculação normativa que protege o consumidor em geral, e, em especial, o idoso adquirente de remédios.

Não se trata de cair na tentação da "aproximação absolutista"(9), tão criticável porque supōe que uma mera qualificação jurídica possa se converter numa mudança social qualitativa independentemente das vicissitudes da vida econômica e política, mas de reconhecer que existem decorrências normativas importantes a partir da definição do constituinte, e que devem constituir metas para a concretização das mesmas.

É indiscutível que a ordem jurídica capitalista, adotada em nossa Constituição, protege a apropriação privada dos bens e resguarda a existência do mercado, espaço social no qual vicejam as relações econômicas com regras e valores específicos, e que tem sua lógica própria de remuneração. Nosso sistema admite a desigualdade de padrōes de renda e de consumo entre as

(7) Na interessante expressão de Carlos Ferreira de Almeida: "A realidade mostra que essa autonomia é tanto menor quanto menos fortes sejam as condições sociais e econômicas dos sujeitos de direitoagentes econômicos, de modo que os mais débeis pouco mais são do que 'sujeitos à sujeição' daqueles outros que dispōem dum poder negocial efetivo". op. cit., p. 13.

(8) Sobre o assunto, vide o excelente trabalho de Daniel Sarmento. Direitos fundamentais e relaçóes privadas. Rio de Janeiro: Lumen Juris, 2004.

(9) Canotilho observa os efeitos perversos derivados da aproximação absolutista ao significado jurídico dos direitos sociais, esta "aproximação absolutista" consiste em confiar na simples interpretação de normas consagradoras de direitos sociais para, através do procedimento hermenêutico de atribuição de significado e enunciados lingüísticos-normativos, (sic), deduzir a efetividade dos mesmos direitos." CANOTILHO, J. J. op. cit.p. 105. 
pessoas e as regiōes, porque aceita a inexorável realidade da pluralidade de desempenho econômico e social. Ora, a imposição de padrões de consumo a todas as pessoas sem observar a singularidade de cada indivíduo nunca foi factível, nem mesmo nas experiências de socialismo real, porque sempre houve "os mais iguais", na mordaz crítica orwelliana.

Mas, ao mesmo tempo em que o Estado Democrático de Direito, abandonando um pouco a sua gênese primeira ${ }^{(10)}$, transige com o modelo econômico do capitalismo, também objetiva imprimir em sua funcionalidade a noção de que todas as práticas econômicas e sociais devem respeitar a dignidade da pessoa humana.

Já tivemos a oportunidade de assim nos pronunciar(11): "Destaca Antonio Pérez Luño(12) que o Estado democrático de direito prescinde do vínculo a um modelo econômico. Na verdade, o fundamento do Estado democrático de direito é ter um compromisso efetivo com a maior inclusão dos cidadãos nos desígnios políticos do Estado. Isso não quer dizer que a dimensão econômica deixe de ter relevância, posto que se reconhece o direito ao mínimo essencial(13), ou seja, na vida concreta de cada um se deve ter as condiçōes materiais que permitam o desenvolvimento de sua personalidade, em uma primeira expressão da dignidade da pessoa humana. Mas, ao pretender franquear os verdadeiros centros de poder a um número cada vez maior de cidadãos, o Estado democrático de direito pode ensejar novas prioridades e metas da Administração Pública, bem como novas restrições ao exercício do poder econômico. Portanto, a radicalização da democracia ${ }^{(14)}$ pode importar

(10) Elias Diaz afirmava que "el paso progresivo del capitalismo al socialismo será asi paralelamente el paso al Estado democrático de Direito". DIAZ, Elías. op., cit.p. 131, o que também era explicitamente reconhecido nas primeiras versões da Constituição da República Portuguesa. Como demonstra a segunda versão do art. 2 na redaçāo da LC n. 1 /82: "A República Portuguesa é um Estado de direito democrático, baseado na soberania popular, e na garantia dos direitos e liberdades fundamentais e no pluralismo de expressão e organização política democráticas, que tem por objetivo assegurar a transição para o socialismo mediante a realização da democracia econômica, social e cultural e o aprofundamento da democracia participativa."

(11) Ação civil pública e compromisso de ajustamento de conduta. Rio de Janeiro: Forense, 2002.

(12) Cf. PÉREZ LUÑO, Antonio E. Derechos humanos, estado de derecho y constitución. Madrid: Tecnos, 1995. p. 231.

(13) Consoante leciona o professor Ricardo Lobo Torres: "O problema do mínimo existencial se confunde com a própria questão da pobreza ... O mínimo existencial não tem conteúdo específico. Abrange qualquer direito, ainda que originariamente não-fundamental (direito à saúde, à alimentação etc.), considerado em sua dimensão essencial e inalienável. Sem o mínimo necessário à existência cessa a possibilidade de sobrevivência do homem e desaparecem as condiçōes iniciais da liberdade. A dignidade humana e as condições materiais da existência não podem retroceder aquém de um mínimo, do qual nem os prisioneiros, os doentes mentais e os indigentes podem ser privados. O fundamento do direito ao mínimo existencial, por conseguinte, reside nas condiçōes para o exercicio da liberdade, que alguns autores incluem na liberdade real, na liberdade positiva ou até na liberdade para ao fito de diferençá-las da liberdade que é mera ausência de constrição." (grifos do autor) Curso de direito tributário e financeiro. Rio de Janeiro: Renovar, 1993. p. 57-58.

(14) A radicalização da democracia não tem apenas o viés econômico, mas considera que a igualdade de condiçōes econômicas é fundamental como anota David Trenc. "Most importantly, radical democrats claim that democratic principles underlie critiques of capitalism and that the creation of an egalitarian 
em uma nova lógica de desenvolvimento econômico, mas não conduzir necessariamente ao socialismo. O Estado democrático de direito, para honrar o seu atributo democrático, não pode, contudo, se demitir de promover as medidas necessárias para a inclusão social, posto que o mercado delas jamais se ocupará. O Estado deve prover a todos, da forma eleita como a melhor pela maioria, a igualdade no sentido de que todos tenham a mesma oportunidade de fazer uso de seus direitos, e não só os individuais, como também os coletivos, resgatando a acepção liberal do 'fair value ${ }^{(15)}$ de direitos repartidos com paridade de John Raw/s ${ }^{(16) " .}$

O princípio da dignidade da pessoa humana, fundamento de nossa República (art. 1․, III da CF/88), foi invocado na decisão sob comento pela Ministra Ellen Gracie e realmente desempenha um importante papel na esfera de proteção do idoso consumidor de remédios. A grosso modo, relembrando as conhecidas lições de Kant sobre o tema, a dignidade é atributo daquilo que não tem preço. Seria paradoxal, assim, falarmos de dignidade em tema correlato à circulação de riquezas? Não seria algo lesivo à idéia de liberdade de iniciativa e de concorrência conforme postularam os antagonistas da lei e o Ministro Marco Aurélio? Andou bem o plenário do Supremo ao responder negativamente a esta questão, porque determinados valores que integram a dignidade do Homem contemporâneo, como é o caso da saúde e da própria vida, só podem lhe ser assegurados se houver um consumo mínimo. Assim, a degradação material de um Homem reduzido a uma condição de miséria absoluta afronta a sua dignidade.

O constitucionalista alemão J. Isensee considera a noção de um mínimo existencial, ao lado de outras categorias que povoam o universo da dogmática contemporânea dos direitos sociais, uma espécie de "camaleão normativo"(17), por ser expressão tão imprecisa, sujeita a modelações políticas conjunturais, nos mesmos moldes da mudança de aparência do pequeno réptil. Ora, não se pode erradicar de plano essa vagueza conceitual, porque seus contornos realmente dependem de elementos culturais e normativos, e não majoritariamente de elementos de ordem descritiva, que são sabidamente mais objetivos. Essa dificuldade, no entanto, não desmerece essa espécie de conceito jurídico indeterminado. O desafio de cada geração é estabelecer qual o consenso de mínimo existencial que deve prevalecer, quais são os direitos e bens que devem ser a todos garantidos para permitir uma existência digna.

society will entail extending these democratic principles into ever expanding areas of daily life: work, education, leisure, the home." (Mais importantemente, democratas radicais defendem que os princípios democráticos pressupōem críticas ao capitalismo e a criação de uma sociedade igualitária implicará a extensão desses princípios democráticos a áreas cada vez mais expansivas da vida diária: trabalho, educação, lazer e a casa.). Tradução livre da autora. TREND, David. Radical democracy: Identity, citizenship, and the State. New York: Routledge, 1996. p. 3.

(15) "valor justo".

(16) RAWLS, John. A theory of justice. Oxford: Oxford University Press, 1972.

(17) Apud, Canotilho, J. J.p. 101. 
O consumo mínimo seria a aplicação da idéia de um mínimo existencial nas relações de consumo. Mas cabe questionar: seria possível criar obrigações para outros, além do Estado? Como se daria a proteção do direito de consumo mínimo face aos demais agentes econômicos?

Para os estreitos lindes do presente comentário, basta-nos recordar que é indiscutível que a autonomia privada, quando ligada a interesses patrimoniais ${ }^{(18)}$, pode ser vinculada à realização de interesses socialmente úteis, e tanto mais intensa será essa vinculação quanto mais relevantes forem tais valores ${ }^{(19)}$. Assim, é plenamente admissível que se limite a autonomia privada em favor de um determinado direito fundamental. Logo, a existência do consumo mínimo pode vincular o particular. Vale lembrar a afirmação de Sarmento no sentido de que "a eficácia dos direitos sociais nas relações privadas presta-se para fundamentar a constitucionalidade das normas que, em favor destes direitos, impuserem limitações à autonomia privada dos agentes econômicos ou criarem obrigaçōes positivas para os mesmos"(20). Portanto, o Estado do Rio de Janeiro pode, em nome da proteção da vida e da saúde dos idosos, estabelecer uma política pública que limite de forma razoável a liberdade dos agentes econômicos de fixarem os preços de bens essenciais como os remédios.

Além disso, a proteção aos direitos sociais deve influenciar a interpretação das normas infraconstitucionais incidentes sobre as relações privadas. Assim, havendo mais de um caminho interpretativo a se seguir deve-se privilegiar aquele que promove a tutela do direito social. O que justamente ocorreu nesta importante decisão da maioria do Supremo Tribunal Federal.

Resta-nos examinar brevemente as seguintes observações anotadas pelo Ministro Marco Aurélio: a) o Estado não pode transferir ao particular o ônus de atender ao direito à saúde das pessoas; b) o favorecimento dos consumidores em virtude da idade não se afigura razoável, porque outras pessoas que estão fora da faixa etária prevista na lei e que não têm condiçōes financeiras não obterão o mesmo tratamento; e c) o desconto pode ensejar aumento para outros consumidores, o que é indesejável para fins da estabilidade da moeda.

Quanto à primeira ponderação já nos manifestamos em favor da vinculação dos particulares à proteção dos direitos fundamentais, sendo plena-

(18) Danie/Sarmento inteligentemente distingue a incidência da limitação da autonomia privada caso a mesma se refira a interesses patrimoniais ou a liberdades existenciais. SARMENTO, Daniel. op. cit.

(19) No mesmo sentido Sarmento: "Ademais, no que se refere às relaçōes patrimoniais, parece-nos possível divisar uma proteção mais forte da autonomia privada quando estiverem em jogo bens de caráter supérfluo para a personalidade humana. Quando, ao contrário, a questāo envolver bens essenciais para a vida humana, a tutela conferida à autonomia privada será menos, aceitando-se um dirigismo estatal mais intenso, voltado para a promoção da solidariedade social e para a busca do bem comum. SARMENTO, Daniel. op. cit. p. 218.

(20) SARMENTO, Daniel. op. cit.p. 341. 
mente admissível a adoção de políticas públicas que limitem direitos de pessoas cuja atividade econômica seja de relevante interesse para a sociedade. No caso, resta evidente que o Estado tem a responsabilidade primeira com a distribuição gratuita de medicamentos e que o advento da lei carioca não operou o mero repasse das responsabilidades do poder público aos particulares, mas ensejou uma maior responsabilidade de quem opera com atividade de absoluto relevo social, como a venda de medicamentos.

A eleição do critério etário não se afigura desmedida quando se trata de proteção de uma parcela da sociedade que, via de regra, está numa posição de maior fragilidade econômica. Essa presunção é adotada pelo próprio constituinte, que conhecendo a realidade de nossos idosos, correlaciona o avanço da idade com o empobrecimento da pessoa. Assim, a própria Constituição garante a gratuidade no transporte público para maiores de 65 , sem investigar a capacidade econômica do usuário do transporte. É notório o peso que os gastos com saúde tem no orçamento dos idosos, sendo razoável a adoção de uma política de desconto de medicamentos em favor dessas pessoas.

É inegável que o desconto no preço de medicamentos também interessa a outros segmentos da nossa sociedade, sobretudo por vivermos em um país pobre e com tanta discrepância social. Mas, não houve afronta ao princípio da isonomia, uma vez que o critério da idade avançada já foi adotado pelo constituinte como determinante de um dever de especial cuidado pelo Estado, pela sociedade e pela família.

À evidência que por não se poder estender a política de desconto obrigatório a todos não se deve deixar desprotegida aquela parcela da sociedade que mais necessita deste tipo de política. Data venia, a tese contrária é um argumento sofista e que não conduz ao resultado interpretativo mais justo que a norma enseja. Afinal, o maior compromisso do exegeta da norma jurídica deve ser trilhar o caminho interpretativo que mais favoreça à construção de um cotidiano mais justo para todas as pessoas. Felizmente, na decisão examinada prevaleceu a justiça para as pessoas idosas do Rio de Janeiro, sem que um sacrifício insuportável fosse imposto às farmácias e drogarias daquele Estado nem à estabilidade monetária de nosso país. 